\title{
Rapid transcriptional autoregulation of a yeast metalloregulatory transcription factor is essential for high-level copper detoxification
}

\author{
Pengbo Zhou and Dennis J. Thiele ${ }^{1}$ \\ Department of Biological Chemistry, University of Michigan Medical School, Ann Arbor, Michigan 48109-0606 USA
}

\begin{abstract}
Copper detoxification in the yeast Candida glabrata is carried out in large part by a family of metallothionein (MT) genes: a unique MT-I gene, a tandemly amplified MT-IIa gene, and a single unlinked MT-IIb gene. In response to elevated environmental copper levels, members of this MT gene family are transcriptionally activated by a copper-dependent, sequence-specific DNA-binding transcription factor, AMT1. AMT1 shares several structural and functional features with the Saccharomyces cerevisiae copper metalloregulatory transcription factor ACE1, which is constitutively expressed and poised for rapid transcriptional responses to the toxic metal copper. In this paper, we demonstrate that $A M T 1$ is subject to positive transcriptional autoregulation, which is exerted through binding of copper-activated AMT1 to a single copper responsive element in the AMT1 promoter. A nonautoregulatory amt1 mutant displayed a marked decrease in both copper tolerance and expression of the MT-II genes, which are critical for high-level copper detoxification in Candida glabrata. Kinetic analysis demonstrated the remarkably rapid AMT1 mRNA accumulation in the presence of copper, which is followed by increased expression of the metallothionein gene products. These results demonstrate that $A M T 1$-positive autoregulation plays a critical role in metal detoxification and suggest that the rapid autoactivation of the AMT1 metalloregulatory transcription factor biosynthesis is essential for C. glabrata to quickly build up a cellular defense line to protect cells upon exposure to high environmental copper levels.
\end{abstract}

[Key Words: AMT1; autoregulation; Candida glabrata; copper; metalloregulatory transcription factor; metallothionein]

Received April 20, 1993; revised version accepted June 22, 1993.

A common response of cells to fluctuations in the levels of nutrients, toxins, or developmental signals is to reprogram the transcription of genes important for coping with the altered environment. In many cases, these genes encode both proteins that directly facilitate the adaptive or developmental response and regulatory genes encoding DNA-binding transcription regulation factors that control the expression of the structural genes (Angel et al. 1988). The metallothioneins (MTs) provide an important system to study the homeostatic processes that regulate cell responses to both essential and toxic metal ions and the mechanisms by which these signals are interpreted and transduced.

MTs are low-molecular-weight, cysteine-rich proteins that bind copper and other metal ions and therefore protect cells against metal toxicity (Kägi and Koiima 1987; Kägi and Schaffer 1988). Expression of MTs is activated, primarily at the level of gene transcription initiation, in

${ }^{1}$ Corresponding author. response to elevated levels of copper, zinc, mercury, and many other metals (for review, see Thiele 1992). The baker's yeast Saccharomyces cerevisiae contains a single MT gene, designated CUP1 (Fogel and Welch 1982; Butt et al. 1984; Karin et al. 1984). In response to elevated copper concentrations, the CUP1 gene is transcriptionally induced by a copper-activated sequence-specific DNA-binding transcription factor denoted ACE1 (Thiele 1988, 1992). Upon the binding of copper through its amino-terminal cysteine-rich metal-binding domain, ACEl is thought to undergo a conformational change, which acts as a "functional switch" from apo-ACE1 to an active protein competent for specific DNA-binding to four independent sites within the CUP1 upstream activation sequence $\left(\mathrm{UAS}_{\mathrm{CUP1}}\right.$ ) (Fürst et al. 1988; Huibregste et al. 1989; Szczypka and Thiele 1989; Buchman et al. 1990; Evans et al. 1990; Hu et al. 1990; Thiele 1992). Previous experiments demonstrated that $A C E 1$ exists as a single-copy gene in $S$. cerevisiae strains harboring either one copy $\left(\right.$ cup $\left.1^{s}\right)$ or multiple tandem copies $\left(C U P 1^{R}\right)$ of CUP1 (Thiele 1988). Besides CUP1, ACE1 directly 
activates transcription of another gene, denoted SOD1, which encodes the copper-zinc superoxide dismutase; this protects cells from oxygen toxicity (Gralla et al. 1991). Furthermore, ACE1 biosynthesis is independent of copper, because constitutive levels of ACE1 are detected in $S$. cerevisiae cells growing either in the absence or presence of exogenous copper ions (Szczypka and Thiele 1989|.

The opportunistic pathogenic yeast Candida glabrata provides an excellent system to study copper-dependent MT gene transcription. Like humans and other higher eukaryotes, this yeast harbors a family of MT genes that is divided into classes: a unique MT-I gene and two distinct $M T-I I$ genes, composed of a tandemly amplified $M T$-II $a$ gene and a single unlinked MT-IIb gene (Mehra et al. 1989, 1992). Both the $M T-I$ and $M T-I I$ genes are transcriptionally activated by copper and its electronic analog, silver (Mehra et al. 1989). Recently, we isolated a C. glabrata gene encoding a copper-dependent transcription factor, denoted AMT1, which bears many structural and functional features of the ACE1 protein in S. cerevisiae (Zhou and Thiele 1991). AMT1 is composed of 265 amino acids organized to form two distinct domains; the amino-terminal domain (amino acid residues 1-115) is positively charged and contains the copper-activated DNA-binding function, which delivers monomeric AMT1 to binding sites in the MT target gene promoters. The carboxy-terminal region (residues 116-265) is negatively charged and, by analogy with ACE1, is likely to harbor the trans-activation function (Zhou and Thiele 1991; Zhou et al. 1992). Upon copper treatment, AMT1 binds to two and six binding sites in the MT-I and MT-IIa promoters, respectively, and activates target gene transcription in a copper concentration-dependent fashion (this paper; Zhou et al. 1992). Of the two MT classes in C. glabrata, the MT-II gene family was shown to play a major role in copper detoxification (Mehra et al. 1992). The structural and functional characteristics of AMT1 demonstrate that this protein has dual functions, acting both as a copper sensory molecule and as a transcription activator: It senses the elevated copper levels and directly initiates a genomic response to this signal by activating the transcription of copper detoxification genes (MTs).

To begin to investigate the mechanisms by which metalloregulatory transcription factors activate MT gene families, we analyzed the physiological factors that modulate expression of the $A M T 1$ gene. In contrast to its functional analog ACE1, which is constitutively expressed both at the level of transcription and translation (Szczypka and Thiele 1989), AMT1 mRNA levels are dramatically increased in response to copper or silver, the same metal ions that foster the AMT1-dependent MT-I and $M T-I I$ gene transcription. In this report we demonstrate that $A M T 1$ is rapidly transcriptionally activated by its own gene product through a single binding site in the AMT1 promoter. Furthermore, through the generation of yeast cells in which the sole functional AMT1 gene is incapable of positive transcriptional autoregulation, we have demonstrated that this autoregulatory mechanism is critical for cell survival in the presence of toxic environmental copper concentrations.

\section{Results}

Metal-induced AMT1 expression and binding to the AMT1 promoter

The biosynthesis of the ACE1 metalloregulatory transcription factor from the baker's yeast $S$. cerevisiae is unaltered at the level of transcription or translation by exogenous copper ions (Szczypka and Thiele 1989). This presumably ensures the presence of adequate steadystate levels of existing $\mathrm{ACE} 1$ to rapidly respond to toxic copper ions by directly activating CUP1 transcription. To determine whether the gene encoding the functionally analogous transcription factor from C. glabrata, $A M T 1$, has a similar pattern of expression, we carried out RNA blotting experiments to detect $A M T 1$ mRNA from untreated cells or from $C$. glabrata cells incubated in the presence of metal ions. Figure 1 demonstrates that low steady-state levels of an mRNA species of $\sim 1.0 \mathrm{~kb}$ are detected from untreated cells, the size of which is consistent with a mRNA encoding the 265-amino-acid AMT1 polypeptide. However, in cells treated with either copper or silver, steady-state levels of the AMT1 mRNA were elevated 16-fold over levels detected in untreated cultures as determined by scanning densitometry. The addition of cadmium salts at the same final concentrations had no discernible effect on AMT1 mRNA levels. Confirming our previous results for ACE1 in $S$. cerevisiae, readily detectable mRNA levels were observed from untreated cultures, which were not significantly affected by the addition of exogenous metals (Fig. 1, bottom). These observations demonstrate that copper and silver, the same metals that activate AMT1 to bind to and activate transcription of the C. glabrata MT-I and MT-IIa genes (Zhou and Thiele 1991; Zhou et al. 1992),

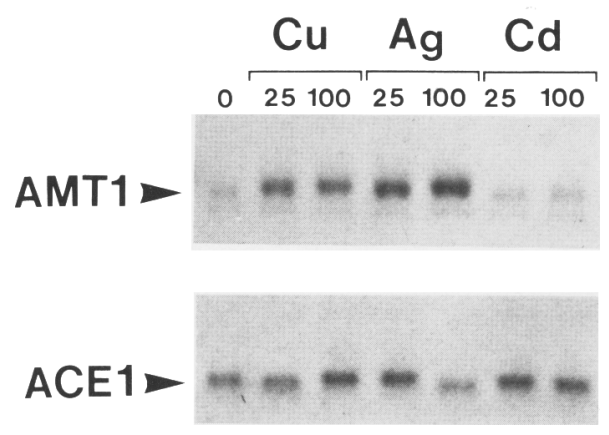

Figure 1. Increased accumulation of the AMT1 mRNA in response to copper $(\mathrm{Cu})$ and silver $(\mathrm{Ag})$. Total RNA was prepared from logarithmic phase cultures of C. glabrata $85 / 038$ and $S$. cerevisiae DTY7 cells untreated or incubated in the presence of the indicated metal, and concentrations are indicated at the top of each lane. The AMT1 or ACE1 mRNA species were detected by RNA blotting and hybridization with $A M T 1$ - or ACE1-specific DNA probe, and are indicated by arrowheads at left. 
also induce accumulation of the $A M T 1$ mRNA steadystate levels in vivo.

\section{Mapping of the AMT1-binding site in the AMT1 promoter}

Recently, we demonstrated that AMT1 is essential for copper-responsive transcription of the MT gene family in C. glabrata through metal-activated DNA-binding to MT gene promoters (Zhou et al. 1992). This finding, in conjunction with the observation that $A M T 1$ mRNA levels are dramatically induced in response to copper or silver, suggests that transcription of the $A M T 1$ gene itself is also subject, directly or indirectly, to regulation by copper. To test whether the AMT1 gene is a direct target for binding of copper-activated AMT1, we carried out DNA-binding studies by electrophoretic mobility shift assays. A 326-bp BgIII-SspI DNA restriction fragment $1-457$ to -130 relative to the AMT1 transcription initiation site) was radiolabeled and used as a probe in electrophoretic mobility shift assays using partially purified AMT1 protein produced in E. coli (Zhou et al. 1992). We detected the formation of a single copper- or silver-dependent DNA-protein complex and no further complexes, even at high extract concentrations/data not shown). Cadmium, however, failed to induce any DNA- protein complex formation. This experiment demonstrated that copper- or silver-activated AMT1 directly interacts with a sequence in the AMT1 promoter, consistent with direct AMT1 metal-dependent positive autoregulation. Furthermore, a copper (Cu)-AMT1 complex failed to form with a ${ }^{32}$ P-labeled 169-bp SspI-RsaI DNA restriction fragment (Zhou and Thiele 1991), which encompasses the downstream AMT1 promoter fragment $\mid-131$ to $+39 \mid$, including the putative TATA box $(-84$ to -79$)$ (data not shown). To specifically locate the AMT1-binding site in the AMT1 promoter, we employed DNase I footprinting assays using partially purified AMT1 protein produced in Escherichia coli (Zhou et al. 1992). As shown in Figure 2A, copper-activated AMT1 protein protected a major region, from -195 to -180 on the coding strand and from -200 to -180 on the noncoding strand of the AMT1 promoter against DNase I cleavage. This AMT1 recognition sequence is highly similar to a consensus AMT1-binding site derived from in vitro DNase I footprinting assays of the MT-I and MT-IIa promoters, which contains a conserved "GCTG" core sequence preceded by an A/T-rich region (Zhou et al. 1992; Fig. 3A). Furthermore, two nucleotides (G-205 and A-204) on the coding strand and one nucleotide (T207) on the noncoding strand were also protected by copper-activated AMT1 (Fig. 2A). Interestingly, 3 bp up-
Figure 2. Copper-activated AMT1 binds to a single site in the $A M T 1$ promoter. $(A)$ DNase I footprinting of the AMT1 promoter region. Footprinting reactions were carried out with either the ${ }^{32} \mathrm{P}$-labeled coding strand (CODING) or noncoding strand (NONCODING) of the AMT1 promoter fragments and the indicated amounts of the AMT1 extract (in micrograms| at the top of each lane. Binding reactions were carried out in the absence $(-)$ or presence $(+)$ of $50 \mu \mathrm{M} \mathrm{CuSO}_{4}$ at room temperature for $10 \mathrm{~min}$. $\mathrm{G} / \mathrm{A}$ is the chemical sequencing reaction displaying adenine and guanine residues using the coding or noncoding probe fragments as templates. Solid vertical lines and numbers indicate the positions of the $\mathrm{Cu}-$ AMT1-protected regions relative to the AMT1 transcription initiation site. $(B)$ Methylation interference analysis of the Cu-AMT1 complex and the AMT1 promoter. The coding and noncoding $A M T 1$ probe fragments, either free $(F)$ or bound with Cu-AMT1 $|C|$, were partially methylated with dimethylsulfate, isolated on electrophoretic mobility shift assay gels, cleaved with piperidine, and analyzed on a $6 \%$ sequencing gel. The numbers and arrowheads indicate positions of critical $\mathrm{G}$ or A residues which, when methylated, interfere with $\mathrm{Cu}-\mathrm{AMT} 1$ binding.
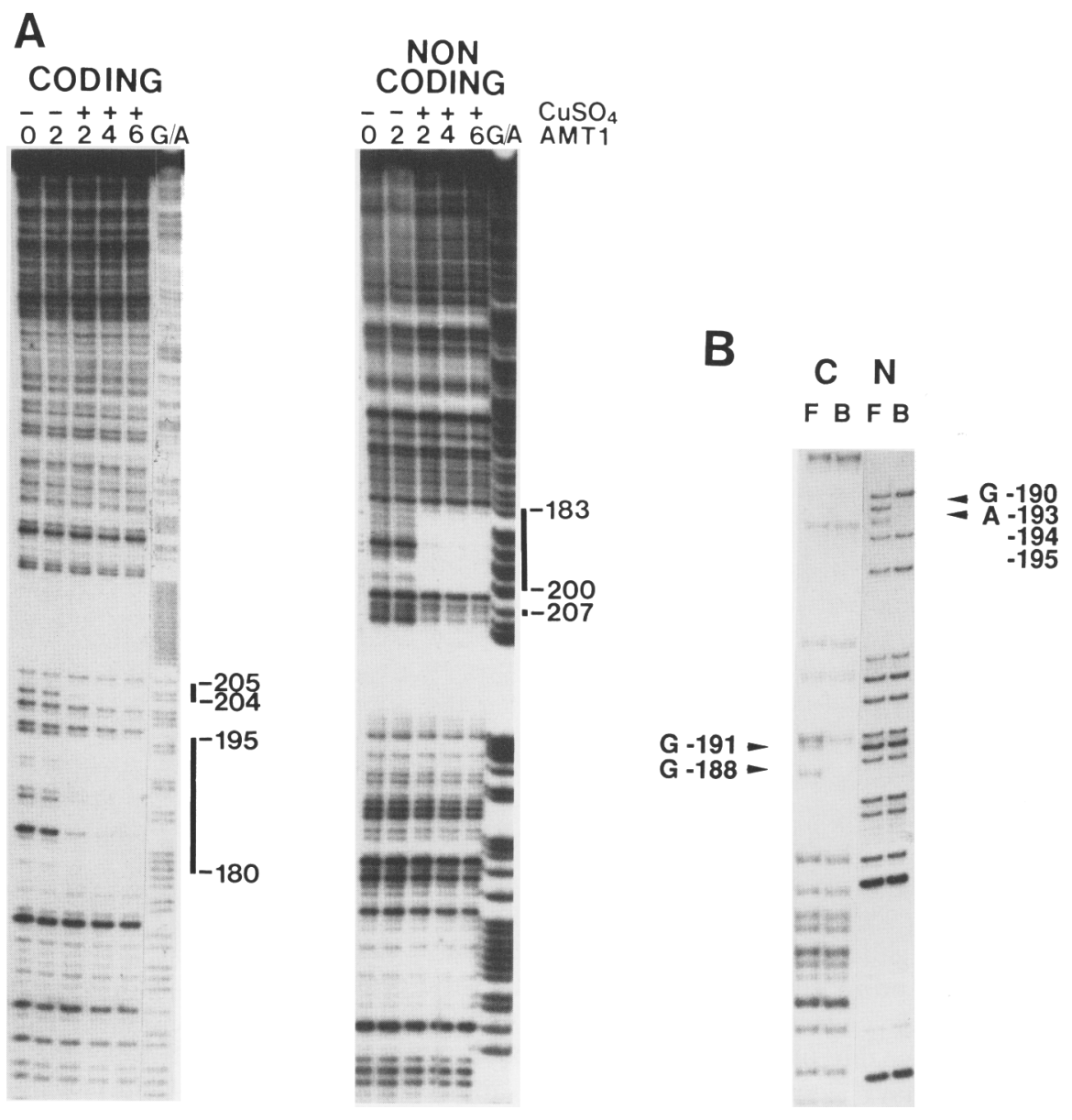
A

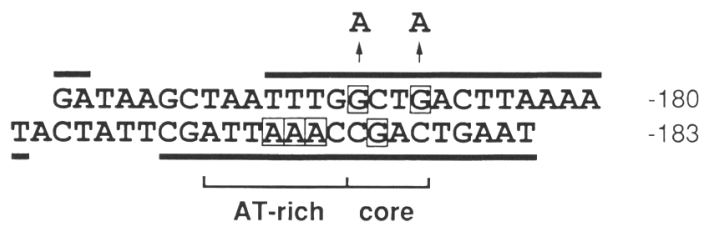

B

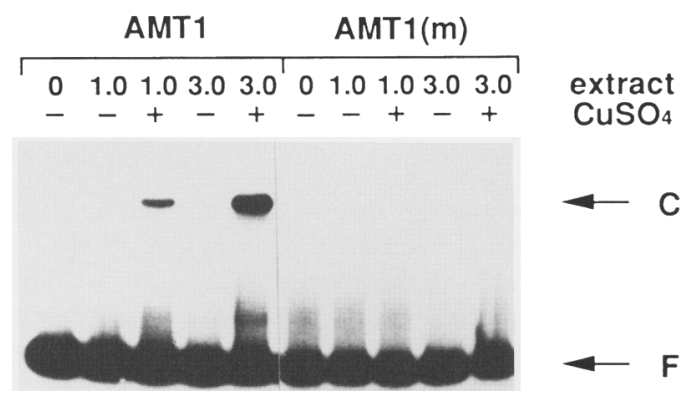

Figure 3. Copper-activated AMT1 fails to bind to the $A M T 1(\mathrm{~m})$ promoter. (A) Sequence of the AMT1-binding site in the AMT1 promoter. Base pairs are numbered relative to the AMT1 transcription start site. Solid horizontal bars indicate the regions within the $A M T 1$ promoter protected by $\mathrm{Cu}-\mathrm{AMTl}$ from DNase I cleavage. Boxed residues are guanines and adenines, which, when methylated, interfere with copper-activated AMTl-binding in vitro. The two brackets indicate the two conserved domains within the AMT1 recognition sequence that are derived from comparison of the AMTl-binding sites in the AMT1, MT-I, and MT-IIa promoters (Zhou et al. 1992). The two A's above the arrows represent the two point mutations introduced to the AMT1-binding site by site-directed mutagenesis to derive the $A M T 1(\mathrm{~m})$ promoter fragment. $(B)$ Electrophoretic mobility shift assays using ${ }^{32} \mathrm{P}$-labeled $A M T 1$ promoter fragments containing either the wild-type (AMT1) or mutant [AMT1(m)] AMT1-binding sites. The amount of AMT1 extract, (indicated in $\mu \mathrm{g}$ ) was used in binding reactions with $(+)$ or without $\left(-\mid 100 \mu \mathrm{M} \mathrm{CuSO}_{4}\right.$. $(F)$ Free probe DNA; $(C)$ copper-activated AMT1 complexed to the wild-type AMT1 promoter.

stream of the $5^{\prime}$ extreme region of the AMT1-binding site lies a nucleotide sequence $(-225$ to -210$)$ composed exclusively of 16 adenine residues. This region is completely resistant to DNase I cleavage even in the absence of $\mathrm{Cu}-\mathrm{AMT} 1$. Whether this poly(A) stretch plays any functional role with respect to $A M T 1$ promoter activity is not currently known.

To determine the nucleotides in the single AMT1binding site important for stable AMT1-AMT1 promoter-DNA interactions, we carried out methylation interference assays using the same ${ }^{32} \mathrm{P}$-labeled $A M T 1$ promoter fragments used for the DNase I footprinting analysis (Fig. 2B). Methylation of the guanine residues in the GCTG core-binding sequence (G-191 and G-188 on the coding strand and G-190 on the noncoding strand) strongly interfered with $\mathrm{Cu}-\mathrm{AMT1}$ binding to its target sequence. Formation of this complex was also inhibited by methylation of A-195, A-194, and A-193 on the noncoding strand. Because the positions for methylation by dimethylsulfate are $\mathrm{N}-7$ on guanine and $\mathrm{N}-3$ on adenine, which are located in the major and minor grooves of B-form double helical DNA, respectively, this methylation interference assay also provided information on which regions of the binding site are in close proximity to bound copper-activated AMT1 protein (Thanos and Maniatis 1992). The observation that all of the critical G or A residues, as ascertained by methylation interference, are found within an 8-bp region suggests that $\mathrm{Cu}-$ AMTI interacts with adjacent major and minor groove DNA, representing both core and A/T-rich domains of the AMT1-binding site, respectively (Fig. 3A).

\section{AMT1-positive autoregulation is mediated by the single AMT1-binding site}

To examine the functional significance of the AMT1binding site in the $A M T 1$ promoter, we converted residues G-191 and G-188 in the core-binding domain, the integrity of which is critical for binding as demonstrated by methylation interference analysis, to adenines by site-directed mutagenesis (Fig. 3A; Ausubel et al. 1987). The 326-bp AMT1 promoter fragments containing either the mutant or wild-type AMT1-binding sites, designated AMT1 $(\mathrm{m})$ or AMTl, respectively, were radiolabeled and subjected to electrophoretic mobility shift assays using the partially purified AMTl protein produced in E. coli. As shown in Figure 3B, mutation of the critical guanine residues in the core domain of the AMT1-binding site abolished $\mathrm{Cu}-\mathrm{AMT1}$ binding to the $A M T 1(\mathrm{~m})$ promoter fragment. The wild-type $A M T 1$ promoter fragment gave rise to a single $\mathrm{Cu}-\mathrm{AMT1}$-dependent complex.

To ascertain the role of this binding site in AMT1 metal-responsive transcriptional autoregulation, we constructed reporter gene fusions between a 613-bp BglIIStyI DNA restriction fragment containing the AMT1 wild-type or $A M T 1(\mathrm{~m})$ promoters and a portion of the AMTl-coding region, in-frame with the $E$. coli lacZ gene, encoding $\beta$-galactosidase (Fig. 4). These two reporter constructs were independently inserted into a $S$. cerevisiae plasmid, pRS316 (Sikorski and Hieter 1989), which is episomally maintained in multiple copies in $C$. glabrata (P. Zhou, M. Szczypka, R. Young and D.J. Thiele, in prep.). The resulting plasmids were then transformed into a C. glabrata strain harboring a ura3 gene mutation for plasmid selection and maintenance, but which has a wild-type $A M T 1$ locus. Total RNA was prepared from the recipient cells either untreated or induced with $100 \mu \mathrm{M} \mathrm{CuSO}{ }_{4}$, and steady-state mRNA levels driven from the $A M T 1-1 a c Z$ and $A M T 1(\mathrm{~m})-1 a c Z$ fusions were detected by primer extension assays using an oligonucleotide primer complementary to the lacZ genecoding strand. Copper-induced $A M T 1-l a c Z$ mRNA accumulation was observed in recipient cells harboring the wild-type AMT1-lacZ fusion and yielded two clusters of AMT1-lacZ mRNA start sites, which correspond precisely to authentic AMT1 mRNA start sites beginning at -54 and -79 relative to the ATG translation initiation codon (Fig. 4). However, no copper-dependent mRNA accumulation was observed to be driven from the $A M T 1(m)-l a c Z$ fusion gene. These results demonstrate 
Figure 4. A functional AMT1-binding site is required for copper-activated transcription driven by the AMT1 promoter. (Left) Schematic representation of the $A M T 1$ or $A M T 1(m)$ promoters fused in-frame to the E. coli $\beta$-galactosidase gene (lacZ). pRS316 is the C. glabrata episomal plasmid that was used as a vector to introduce the $A M T 1-l a c Z$ or $A M T 1(m)-l a c Z$ fusion genes into C. glabrata $\mathrm{Q}$ cells. (Right) The $A M T 1(\mathrm{~m})$ promoter is not responsive to copper. Total RNA was prepared from $C$. glabrata $Q$ recipient cells carrying the pAMT1-lacZ, pAMTl $(\mathrm{m})-\mathrm{lacZ}$, and pRS316 plasmids either untreated $(-)$ or treated $\left(+\mid\right.$ with $100 \mu \mathrm{M} \mathrm{CuSO}_{4}$. Twenty micrograms of each RNA was analyzed by primer extension using a synthetic oligonucleotide complementary to the lac $Z$ mRNA. The two clusters of copper-inducible mRNA species marked by two brackets at left, represent the primer extension products due to the existence of two groups of initiation sites for $A M T 1$ transcription. Dideoxy sequencing reactions (lanes $G, A, T, C$ ) were carried out using pAMT1-lacZ plasmid DNA and the lacZ-specific primer, and were used to map the primer extension products.

that the $A M T 1$ gene is subject to direct metal-dependent transcriptional autoregulation, and this activation is mediated by the single AMT1-binding site in the AMT1 promoter. Furthermore, copper-induced mRNA accumulation from the AMT1-lacZ fusion gene was dependent on a functional endogenous $A M T 1$ gene (data not shown).

Kinetics of accumulation of AMT1,

MT-I, and MT-II mRNAs in response to copper

The known potent toxicity of copper (Kägi and Kojima 1987) dictates that copper detoxification genes must be functionally or biosynthetically activated quickly in response to copper exposure. Because ACE1 is constitutively expressed in $S$. cerevisiae, but $A M T 1$ is highly inducible by copper in C. glabrata, we examined the kinetics of accumulation of $A M T 1$ mRNA and that of its target genes MT-I and MT-II, following copper exposure. Wild-type $C$. glabrata cells were grown in synthetic complete (sc) medium to log phase, induced with $100 \mu \mathrm{M}$ $\mathrm{CuSO}_{4}$, and harvested several times following copper addition; total RNA was prepared, and RNA blotting assays were performed to measure the steady-state levels of $A M T 1, M T-I$, and MT-II mRNAs during the course of copper treatment. The C. glabrata URA3 mRNA levels were also evaluated as a control for the amount and integrity of RNA loaded onto each lane of the RNA gel. As shown in Figure 5, AMT1 mRNA accumulated to maximum levels extremely rapidly after $\sim 5.5 \mathrm{~min}$ of exposure of cells to copper (a 5-min centrifugation was employed to harvest cells). The MT-I mRNA also reached very high levels quickly, although maximal steady-state levels of $M T-I$ mRNA were not detected until $\sim 10 \mathrm{~min}$ after copper exposure. However, high-level accumulation of the MT-II mRNA was only observed $1 \mathrm{hr}$ after copper addition. These results demonstrated that AMT1 gene expression is very rapidly autoactivated upon copper induction. The MT-I gene is also rapidly expressed at high levels followed by an increase in MT-II mRNA accumulation under conditions of $100 \mu \mathrm{M} \mathrm{CuSO}_{4}$ treatment. Because the MT-II probe used in this experiment hybridizes to both the MT-IIa and MT-IIb mRNAs, the level of the MT-II signal that we observed is a combination of the two MT-II mRNA transcripts and, therefore, did not allow us to distinguish between the accumulation of these mRNA species. Because mutation of the AMT1-binding site abolishes metal-dependent AMT1 mRNA accumulation (Fig. 4), we tested the function of a DNA fragment $(-457$ to +161$)$ encompassing the $A M T 1$ promoter in fostering the rapid accumulation of $A M T 1$ mRNA. The AMT1-lacZ fusion gene in the pAMT1lacZ recipient cells was also rapidly induced with kinetics identical to that of the authentic endogenous $A M T 1$

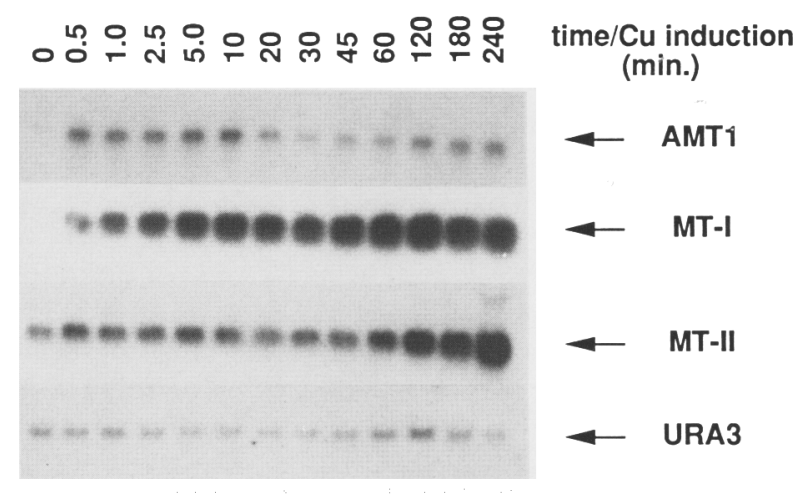

Figure 5. Kinetics of accumulation of the AMT1, MT-I, MT$I I a$, and $M T-I I b$ mRNAs in response to copper exposure. Wildtype C. glabrata $85 / 038$ cells were grown to early logarithmic phase and treated with $100 \mu \mathrm{M} \mathrm{CuSO}_{4}$ for the time (in min) indicated at the top of each lane. Total RNA was prepared, and $30 \mu \mathrm{g}$ was used in RNA blotting assays. AMT1, MT-I, MT-II, and $U R A 3$ (internal control) mRNA species were detected by the corresponding probes. Positions corresponding to each mRNA species are indicated by arrows at right. 
gene as determined by primer extension assays /data not shown). These results strongly suggest that rapid $A M T 1$ metal-dependent autoregulation is largely mediated through the AMT1 promoter-binding site and at the level of transcription initiation.

\section{AMT1 metal-dependent autoregulation is critical for normal copper homeostasis}

Due to experimental complexities, the physiological significance of transcription factor gene autoregulation in higher eukaryotes has not been directly tested in the complete absence of an endogenous functional allele. To determine whether AMT1 transcriptional autoregulation is critical for cellular copper detoxification in C. glabrata, we uncoupled copper-dependent autoactivation from the $A M T 1$ promoter in the context of an intact, single endogenous functional $A M T 1$ gene. This was achieved by introducing the two point mutations in the AMT1-binding site, described in Figure 3A, in the complete $A M T 1$ gene; therefore, this gene is identical to the wild-type AMT1 gene, with the exception of a nonfunctional AMT1-binding site in the $A M T 1$ gene promoter. The wild-type or nonautoregulatory mutant $A M T 1$ genes [AMT1 and $A M T 1(\mathrm{~m})$, respectively] were subcloned into a $C$. glabrata integrative plasmid, $\mathrm{Ul}(\mathrm{b})$, carrying the $C$. glabrata URA3 gene (P. Zhou, M. Szczypka, R. Young, and D. Thiele, in prep.) and inserted at the C. glabrata ura3 locus within a strain in which the endogenous AMT1 gene had been insertionally inactivated (Zhou et al. 1992). The targeted single-copy integration was verified by Southern blotting (data not shown). The resultant isogenic strains are designated $A M T 1:: U R A 3$ and AMT1(m)::URA3, respectively.

We then asked whether $A M T 1$ gene transcriptional autoregulation is critical for the protection of yeast cells in the presence of high environmental copper levels. The copper-resistant phenotype of the isogenic AMT1::URA3 and $A M T 1(m):: U R A 3$ strains, as well as their parental strains C. glabrata 85/038 (wild-type) and amt1-1 (amt1 gene insertionally inactivated), was tested for copper resistance. As shown in Figure 6, the parental wild-type and $A M T 1:: U R A 3$ cells are indistinguishable in their resistance to copper and grow on agar containing up to 1.5 $\mu \mathrm{M} \mathrm{CuSO}_{4}$. These observations demonstrate that integration of the wild-type $A M T 1$ gene at the ura 3 chromosomal locus does not affect its expression or function. The $A M T 1(\mathrm{~m}):: U R A 3$ strain, however, gave rise to a maximal copper resistance level at $400 \mathrm{CuSO}_{4}$, a threeto fourfold decrease compared with the wild-type or AMT1::URA3 strains. As demonstrated previously, the amt1-1 strain is hypersensitive to copper and fails to grow even in the presence of $25 \mu \mathrm{M} \mathrm{CuSO}_{4}$ (Zhou et al. 1992). In these experiments, copper-sensitive cells arrested at the single-cell stage when challenged with toxic concentrations of $\mathrm{CuSO}_{4}$ (data not shown). These results clearly demonstrate that $A M T 1$ gene-positive autoregulation is essential for C. glabrata resistance to high environmental copper levels. The nonautoregulatory $A M T 1$ allele $[A M T 1(\mathrm{~m}):: U R A 3]$, survives on media con-

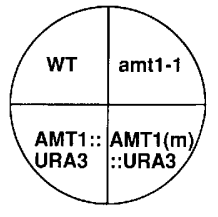

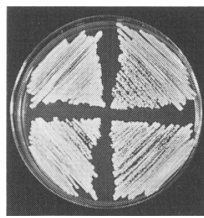

$\mathbf{0}$

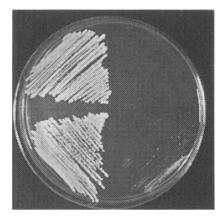

$300 \mu \mathrm{M}$

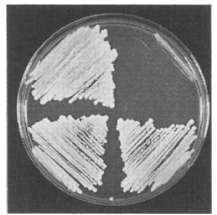

$25 \mu \mathrm{M}$

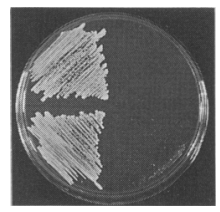

$500 \mu \mathrm{M}$

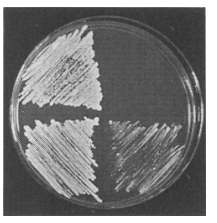

$200 \mu \mathrm{M} \quad \mathrm{CuSO}_{4}$

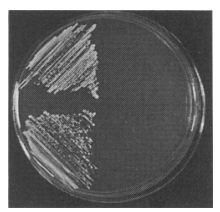

$1 \mathrm{mM} \mathrm{CuSO}_{4}$
Figure 6. AMT1 autoregulation is essential for C. glabrata cells to survive on high copper concentrations. The nonautoregulatory $A M T 1(m):: U R A 3$ allele fails to confer wild-type copper resistance to $C$. glabrata. Isogenic $C$. glabrata strains 85/038, amt1-1, AMT1::URA3, and AMT1(m)::URA3 were streaked onto $\mathrm{SC}$ agar and $\mathrm{SC}$ agar containing the concentrations of $\mathrm{CuSO}_{4}$ as indicated. Plates were incubated at $30^{\circ} \mathrm{C}$ for 2 days. The grid indicates the relevant genotypes of the four individual strains streaked onto each sector of the plates.

taining $\sim 10$ times the concentration of exogenous copper as the amt1-1 strain. Although the mutation in the AMT1 promoter abolishes $A M T 1$ binding and autoactivation, the $A M T 1(\mathrm{~m}):: U R A 3$ allele drives the expression of the $A M T 1$ mRNA and, presumably, protein, owing to AMTl-independent mechanisms of expression of this gene (see Fig. 7). Consistent with this possibility, we detected the formation of AMT1-independent DNA-protein complexes using whole cell extracts from the amt1-1 strain and the $326-\mathrm{bp} A M T 1$ promoter fragment described in Figure 2. Furthermore, the formation of these complexes was not affected by guanine mutations of the core AMT1-binding sequence [AMT1(m) probe; data not shown].

\section{Copper sensitivity of cells unable to autoactivate AMT1 \\ correlates with a defect in MT MRNA accumulation}

Previous studies suggested that because the $C$. glabrata $M T-I$ and $M T-I I$ genes are transcriptionally coinduced by copper in a concentration-dependent manner, the copper-responsive transcriptional activator AMT1 is not limiting in its abundance (Mehra et al. 1989, 1992). Our demonstrations that AMT1 is both transcriptionally positively autoregulated and that this is essential for normal copper resistance suggest that positive autoregulation 

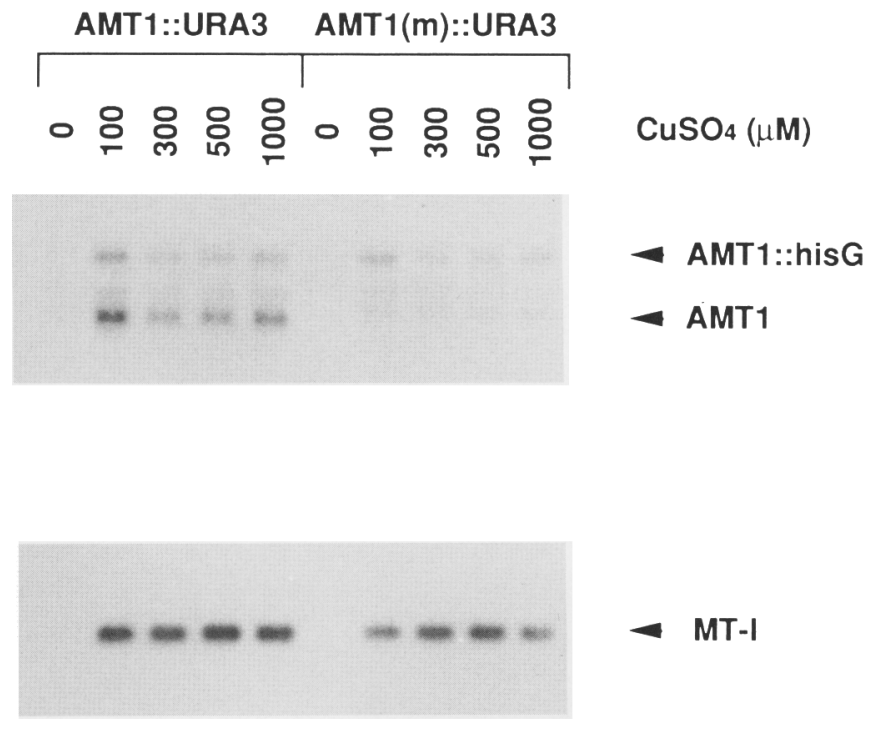

MT-I

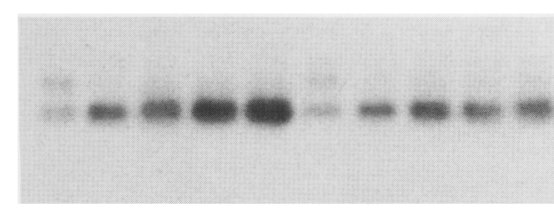

MT-II
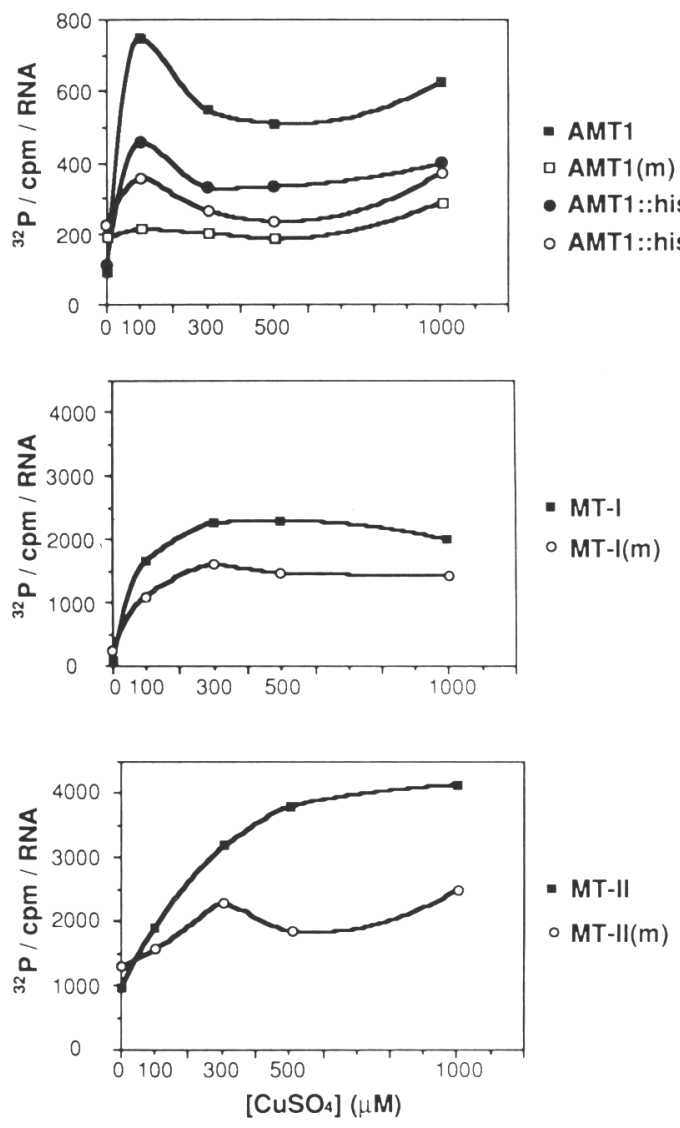

- AMT1

- $A M T 1(m)$

- AMT1::hisG

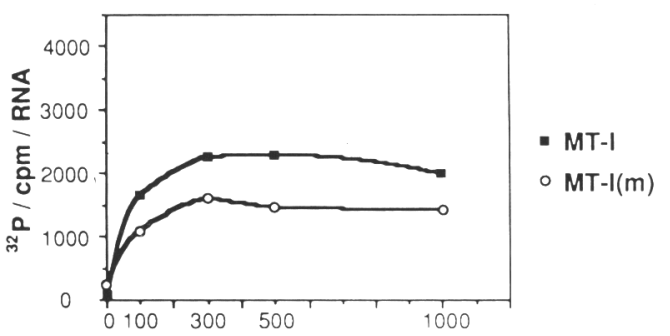

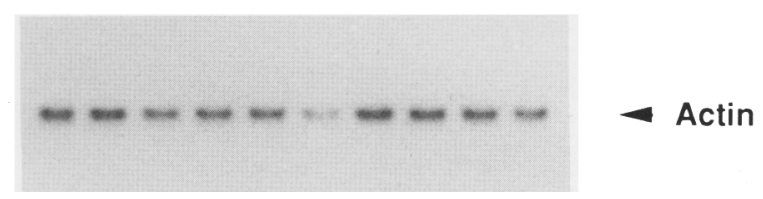

- $A M T 1:$ hisG(m)

Figure 7. Accumulation of the $A M T 1, M T-I$, and $M T-I I a$, and $M T-I I b$ mRNAs in response to increasing copper levels. AMT1::URA3 and $A M T 1(\mathrm{~m}):: U R A 3$ cells were grown in SC medium lacking uracil (SC - ura) to logarithmic phase. Parallel cultures were untreated or treated for $10 \mathrm{~min}$ with the copper concentrations indicated at the top of each lane. Specific $A M T 1, A M T 1:: h i s G, M T-I$, and $M T-I I$ mRNAs were detected by RNA blotting (left). As an internal control for the loading of RNA, C. glabrata actin mRNA levels were analyzed using a hybridization probe derived from the cloned $S$. cerevisiae actin gene, which hybridizes to the $C$. glabrata actin gene (Mason et al. 1987). The radioactivity $(\mathrm{cpm}$ ) associated with each individual mRNA species was quantitated by counting the dried nitrocellulose membranes with a Beta-gen scanner. The amounts of each mRNA species were normalized to the corresponding actin mRNA level and plotted against copper concentration (in $\mu \mathrm{M})$. (Right) The three graphs indicate the steady-state mRNA levels from each gene in response to the range of copper levels. Each mRNA species is represented by the symbol shown at the right of each graph.

may ensure an adequate supply of the AMT1 transcription factor to activate the transcription of C. glabrata copper homeostasis genes. Because free intracellular copper could cause rapid macromolecular damage through redox chemistry (Halliwell and Gutteridge 1984), and $A M T 1$ is expressed at very low levels in the absence of exogenous copper (Figs. 1 and 7), perhaps rapid AMT1 autoregulation is essential for cells to synthesize sufficient AMT1 protein to boost the synthesis of metallothioneins promptly before cells are irreversibly dam- aged by sudden increases in intracellular copper concentrations. To test this hypothesis, we carried out RNA blotting assays to determine the steady-state mRNA levels of the AMT1, MT-I, and MT-II genes after treating the AMT1::URA3 and AMT1(m)::URA3 cells with increasing doses of copper for a brief period of time (10-min induction plus 5-min centrifugation) (Fig. 7, left). The $S$. cerevisiae actin gene, which hybridizes to a single mRNA species in C. glabrata, was used as a control for the amount and integrity of RNA loaded onto each lane 
of the gel in this experiment. Figure 7 (right) shows a quantitation of the steady-state mRNA levels of AMT1, AMT1::hisG, MT-I, and MT-II in AMT1::URA3 and $A M T 1(\mathrm{~m}):: U R A 3$ cells exposed to the range of copper concentrations. The wild-type $A M T 1$ gene integrated at the C. glabrata ura3 locus was highly induced when cells were exposed to copper, reaching a maximal eightfold induction after a $10-\mathrm{min}$ exposure to $100 \mu \mathrm{M} \mathrm{CuSO}_{4}$. The endogenous amt1-1 locus, which carries an insertion of the Salmonella his G gene within the $A M T 1$ open reading frame, synthesized a hybrid $A M T 1::$ his $G$ mRNA whose identity was confirmed by its hybridization to a ${ }^{32}$ P-labeled hisG probe by RNA blotting (data not shown). The expression of this hybrid gene was also induced by copper-activated AMT1 with a similar dose response and a 4.2-fold induction, presumably mediated through the intact AMT1-binding site within the promoter of the his $G$ insertionally inactivated amt1-1 locus. In contrast, no copper-inducible mRNA accumulation was observed for the $A M T 1(\mathrm{~m})$ gene in the AMT1(m)::URA3 strain. However, mRNA driven from the $A M T 1::$ his $G$ hybrid gene accumulated in response to exogenous copper, although there was an induction of only $\sim 1.6$-fold. Low steady-state levels of the AMT1::hisG mRNA were also detected in the amt1-1 strain by RNA blotting upon prolonged exposure and were not altered upon copper treatment (data not shown). These findings demonstrate that copper-induced transcription driven by the $A M T 1$ promoter is dependent on both the presence of a functional AMT1-binding site and a functional AMT1 protein. The AMT1 or AMT1::hisG mRNA levels in the AMT1::URA3 cells were highest when cells were treated with $100 \mu \mathrm{M}$ copper and slightly decreased at higher copper concentrations.

RNA blotting with the MT-I probe showed that the $M T$-I gene was expressed at maximum levels even at low copper concentrations $(100 \mu \mathrm{M})$. The overall level of the $M T-I$ mRNA in the $A M T 1(m):: U R A 3$ strain is $~ 1.4$-fold lower than that in the AMT1::URA3 strain. The $M T-I I$ mRNA levels $(M T-I I a$ and $M T-I I b)$ in these two isogenic strains are similar upon addition of sublethal concentrations of copper, which are 100 and $300 \mu \mathrm{M}$ of $\mathrm{CuSO}_{4} . \mathrm{A}$ reproducible twofold difference of the $M T-I I$ mRNA level was observed when the strains were treated with lethal doses of copper for AMT1(m)::URA3 cells $1500 \mu \mathrm{M}$ and $1 \mathrm{mM})$. It should be noted that $10-\mathrm{min}$ exposure of AMT1(m)::URA3 with $500 \mu \mathrm{M}$ or $1 \mathrm{mM}$ copper did not immediately impair cell growth, as judged by similar increases of $\mathrm{OD}_{600}$ as well as similar levels of actin mRNA observed between AMT1::URA3 and AMT1(m)::URA3 cells following copper treatment. Taken together, these results demonstrate that the $M T-I$ and $M T-I I$ mRNA steady-state levels were significantly compromised in the nonautoregulatory $A M T 1(\mathrm{~m}):: U R A 3$ allele.

\section{MT-I and MT-II protein levels are correspondingly reduced in AMT1 nonautoregulatory cells}

The steady-state levels of MT-I and MT-II protein under copper-induced conditions were analyzed by pulse-label- ing proteins in $A M T 1:: U R A 3$ and $A M T 1(\mathrm{~m}):: U R A 3$ cells with $\left[{ }^{35} \mathrm{~S}\right]$ cysteine, followed by fluorographic analysis on a $25 \%$ native polyacrylamide gel (Fig. 8 ). This experiment demonstrates that the MT-I and MT-II proteins were undetectable in both $A M T 1:: U R A 3$ and AMT1(m)::URA3 cells grown in the absence of copper. Addition of increasing doses of copper resulted in the elevated synthesis of the MT-II protein with a significantly higher MT-II level observed in the AMT1::URA3 cells treated with all copper concentrations than that in the $A M T 1(\mathrm{~m}):: U R A 3$ cells. The MT-I protein reached similar maximum levels upon treatment with low copper $(100 \mu \mathrm{M})$ in both strains, and this level was similar when the strains were induced with higher concentrations of copper. These results parallel the steady-state $M T-I$ and MT-II mRNA levels that we obtained for AMT1::URA3 and AMT1(m)::URA3 cells under the same copper-induced conditions (Fig. 7).

\section{Discussion}

An interesting and important question in gene regulation is how transcription factor genes themselves are regulated, and does this regulation play a key role in the function of the encoded protein? In prokaryotes, autogenous regulation has been demonstrated for several transcriptional repressors and often results in down-regulation of genes encoding these DNA-binding proteins (for review, see Maloy and Stewart 1993). In eukaryotes, positive transcriptional autoregulation has been observed for many transcription factors and is suggested to be an important regulatory mechanism in a large number of biological processes such as cell growth, differentiation, development, and others (for review, see Serfling 1989; Falvey and Schibler 1991). However, efforts to precisely delineate the physiological role of transcription factor autoregulation in these systems have been impeded by the fact that multiple regulatory mechanisms function through the upstream regulatory regions at the same dif-

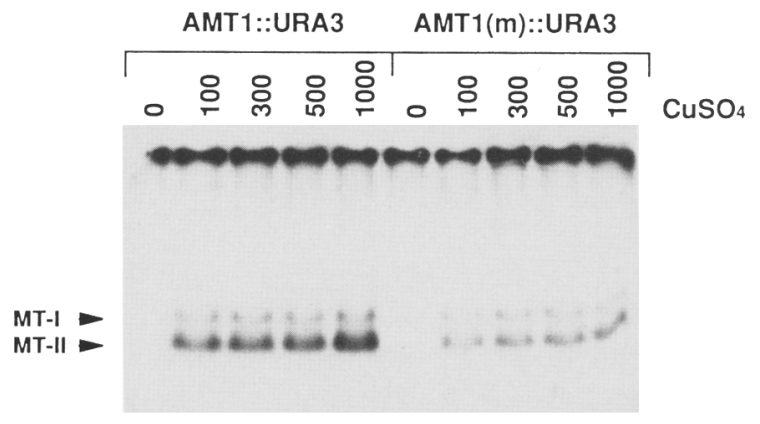

Figure 8. The MT-I and MT-II protein levels in AMT1::URA3 and $A M T 1(m):: U R A 3$ cells in response to copper. $\left[{ }^{35} \mathrm{~S}\right]$ Cysteinelabeled total soluble proteins were prepared from control or copper-treated $A M T 1:: U R A 3$ and $A M T 1(\mathrm{~m}):: U R A 3$ cells at the concentrations indicated at the top of each lane. Each protein extract $(1.0 \mu \mathrm{g})$ was subjected to electrophoresis on a $25 \%$ nondenaturing polyacrylamide gel. The arrowheads at left indicate the MT-I and MT-II protein species. 
ferentiation or developmental stage, and by the difficulty of genetic manipulations in higher eukaryotes, such as gene knockouts and homologous recombination.

As a unicellular eukaryotic microorganism, yeast provides a powerful model system to study gene regulation and other biochemical processes, largely owing to the ease of genetic manipulations. In this work we demonstrated that the AMT1 metalloregulatory transcription factor of $C$. glabrata functions in a positive autoregulatory loop, which is distinct from the constitutively expressed ACE1 gene of S. cerevisiae (Szczypka and Thiele 1989). AMT1 is among the first reported yeast transcription factors that directly participates in its own transcription, and the physiological significance of this autoregulation has been established with respect to its role in activating the transcription of target genes that play a critical role in cell defense mechanisms against metal toxicity. In this paper, we demonstrated that $A M T 1$ autoregulation is mediated by the single AMTl-binding site in the $A M T 1$ promoter and requires functional AMT1 protein.

On the basis of previous studies (Mehra et al. 1989, 1992; Zhou and Thiele 1991; Zhou et al. 1992) and results obtained in this work, we propose the following autoregulatory model for $A M T 1$ expression and the copper-induced transcriptional response in C. glabrata cells. Under normal growth conditions and low environmental copper concentrations, C. glabrata cells synthesize low basal levels of the copper sensory molecule AMT1, as well as MTs and other putative copper homeostatic proteins. MTs may sequester the low concentration of biologically available cellular copper ions preferentially over AMT1, thereby preventing futile transcription of $A M T 1, M T-I, M T-I I$, and potentially other, as yet unidentified, AMT1-dependent copper-regulated genes. High environmental copper concentrations lead to an increased copper accumulation, and intracellular copper ions would be available to apo-AMTl protein produced from basal level transcription of this gene. The coordination of copper by the AMT1 amino-terminal DNAbinding domain activates sequence-specific DNA binding and, once deposited on target gene promoters, first activates transcription of the AMT1 and MT-I genes, followed by the MT-II isoform genes. The specific properties of the $A M T 1$ promoter, either a high-affinity AMT1binding site or interactions with other transcription factors, may enhance the specific affinity of $\mathrm{Cu}$-AMT1 or its transcriptional potency and contribute to the rapid autoactivation of the $A M T 1$ gene. Although the relative in vivo affinity of Cu-AMT1 for the AMT1, MT-I, and MT-II promoters has not yet been determined, the results that we observed for AMT1, MT-I, and MT-II mRNA levels suggest that even at low copper concentrations $(100 \mu \mathrm{M})$, the $A M T 1$ and $M T-I$ genes are rapidly activated to very high levels while the MT-II genes are only partially activated. This observation suggests a possible role of $M T-I$ as a first line of defense to respond to low levels of copper in the environment. Increasing doses of copper treatment result in the elevated synthesis of the MT-II mRNA and protein presumably because the MT-I protein alone is insufficient for sequestering intracellular copper ions. This high-level MT-II gene expression is dependent on two factors: One is the $A M T 1$ autoregulation that produces sufficient apo-AMT1 protein; second is the increasing amount of copper that switches more apo-AMT1 into the transcriptionally competent $\mathrm{Cu}-\mathrm{AMT1}$ available to the $C$. glabrata MTs, especially the tandemly amplified MT-IIa gene. Although the MT-I and MT-II proteins bind cooper efficiently, we cannot exclude the possibility that MT-I, MT-II, or AMT1 proteins, or other proteins encoded by AMT1-dependent genes, have additional activities that protect cells from copper toxicity. Consistent with this possibility, Tamai et al. (1993) have recently demonstrated that $S$. cerevisiae $\mathrm{Cu}-\mathrm{MT}$ protein has potent antioxidant activity. Furthermore, because $\mathrm{Cu}-\mathrm{ACEl}$ activates SOD1 transcription (Gralla et al. 1991), it is possible that $\mathrm{Cu}-\mathrm{AMT1}$ may also activate other target genes, and the decreased tolerance of the nonautoregulatory $A M T 1$ mutant strain to copper may result from defective expression of several copper homeostatic genes regulated by AMT1. Further experiments will determine the relative affinity of $\mathrm{Cu}-\mathrm{AMT} 1$ for the $A M T 1, M T-I$, and $M T$ $I I$ promoters and the precise mechanism by which $A M T 1$ is rapidly transcriptionally autoactivated.

As a copper sensory molecule, AMT1 responds quickly to the increase in intracellular copper levels by an amplification of its own gene product. Although the mechanisms for copper transport and distribution in C. glabrata and other organisms have not been elucidated in detail, copper uptake in $S$. cerevisiae has been demonstrated to be a rapid process, and the rate of intracellular copper accumulation is proportional to the medium copper concentrations (Lin and Kosman 1990). The rapid copper-dependent $A M T 1$ and $M T-I$ transcription suggests that copper uptake in C. glabrata is not rate limiting; therefore, the cells may be immediately subjected to copper toxicity upon addition of copper to the growth media. The rapid AMT1 autoregulation ensures that AMT1 proteins are made promptly and at a concentration sufficient for its function as a copper-dependent transcription factor to stimulate high-level expression of the multiple C. glabrata MT genes before extensive copper-induced cellular damage occurs. Recently, it has been observed that pretreatment of human HeLa H454 cells with a low dose of cadmium results in superinduction of the human MT- $\mathrm{II}_{\mathrm{A}}$ gene in response to subsequent cadmium administration (A. Leone, pers. comm.). This may reflect a similar autoregulatory expression of the gene, or genes, encoding putative metal response element (MRE)-binding proteins in humans and other organisms bearing an MT gene family.

In contrast to $S$. cerevisiae, in which the gene encoding the ACE 1 copper metalloregulatory transcription factor is constitutively expressed (Szczypka and Thiele 1989), $A M T 1$ autoregulation reflects another level of regulatory complexity for copper homeostatic genes in C. glabrata. Although the opportunistic pathogenic yeast C. glabrata and the baker's yeast $S$. cerevisiae are evolutionarily related (Barns et al. 1991), the fact that C. glabrata cells are 
found in a wide variety of habitats including soil, water, on animals and human tissues or organs suggests that this yeast encounters many environmental elements with quite different copper contents (Sinnott et al. 1987). As a unicellular eukaryotic microorganism, a yeast cell is highly accessible to environmental changes in metal concentrations. The development of a rapid positive autoregulatory mechanism for a metal sensing switch, AMT1, could allow C. glabrata to accumulate sufficient amounts of copper when available concentrations are low but respond rapidly when challenged with toxic environmental copper concentrations.

\section{Materials and methods}

Strains, plasmids, and growth conditions

The parental wild-type C. glabrata strain $85 / 038$ was a gift of $P$. Magee (University of Minnesota, St. Paul). The $u r a 3^{-}$(Q) strain and the AMT1 disruption strain amt1-1 were constructed as described in detail (Zhou et al. 1992) and were used as recipient hosts for transformation by $C$. glabrata episomal or integrative plasmids described in the following sections. The amt1-1 strain is the parental strain for the integration of wild-type (AMT1) or mutant $[A M T 1(\mathrm{~m})]$ genes at the ura3 locus to construct isogenic $A M T 1:: U R A 3$ and $A M T 1(m):: U R A 3$ strains by transformation and homologous recombination (Aubusel et al. 1987; P. Zhou, M. Szczypka, R. Young, and D. Theile, in prep.). Yeast cells were grown in rich (YPD) or SC medium lacking uracil (Ausubel et al. 1987). Copper resistance tests, copper treatment, and the length of incubation are described in the respective figure legends. The S. cerevisiae strain DTY7 (Szczypka and Thiele 1989), which contains the wild-type $A C E 1$ and three copies of the tandemly amplified CUP1 genes, was used to examine the mRNA levels from the $A C E 1$ gene under control or metal-induced conditions. $E$. coli strain XL-1 blue (Stratagene) was employed for the construction and maintenance of plasmids using standard techniques (Ausubel et al. 1987).

To study the role that the single AMT1-binding site plays in AMT1 autoregulation, two guanine residues (G-192 and G-189) in the GCTG core-binding sequence were changed to adenines by oligonucleotide-directed mutagenesis using the mutagenic primer 5'- CGCCCACCACTACTTTTAAGTTAGTCAAATTAGC-3', which hybridizes to $A M T 1$ promoter nucleotide positions -201 to -168 relative to the +1 transcription start site (this paper; Ausubel et al. 1987; Zhou and Thiele 1991). The in vivo autoactivation of the $A M T 1$ gene was demonstrated using $A M T 1-l a c Z$ or $A M T 1(m)-l a c Z$ fusion genes containing either the wild-type or mutant AMT1-binding site, respectively. The 616-bp BglII-StyI DNA restriction fragment, which contains the $A M T 1$ or $A M T 1(\mathrm{~m})$ promoter and the first $36 A M T 1$ codons was first blunt-ended at the StyI site by the Klenow fragment of DNA polymerase $I$ and then subcloned into the plasmid YEp356(R) to construct AMT1-lacZ or AMT1(m)-lacZ in-frame fusion genes (Myers et al. 1986). The 4.3-kb HindIII-StuI DNA restriction fragments containing the $A M T 1-l a c Z$ or $A M T 1(\mathrm{~m})-$ $l a c Z$ fusions were subcloned into the $C$. glabrata episomal plasmid pRS316 to make plasmids pAMTl-lacZ and pAMT1(m)lacZ (Sikorski and Hieter 1989). These two pRS316-based plasmids can stably transform the strain Q $\left(\mathrm{ura}^{-}\right)$and replicate in multiple copies in C. glabrata cells (P. Zhou, M. Szczypka, R. Young, and D. Theile, in prep.).

To characterize the biological role of $A M T 1$ autoregulation, two integrative plasmids were constructed as follows: A $4.0 \mathrm{~kb}$ genomic fragment containing the C. glabrata URA3 gene was inserted at the BamHI site of pRS425 to make plasmid U1(b) (Sikorski and Hieter 1989; P. Zhou, M. Szczypka, R. Young, and D. Theile, in prep.). The 1.6-kb BgIII-SpeI DNA restriction fragments containing either the wild-type (AMT1) or mutant [AMT1 $(\mathrm{m})]$ AMT1 genes were then subcloned into U1(b) to make integrative plasmids YIpAMT1::URA3 and YIpAMTl(m)::URA3. These two plasmids were digested to completion with Stul restriction enzyme, which has a unique site located in the URA3 open reading frame to facilitate sequence-specific recombination. The linearized integrative plasmids were integrated in single copy at the URA3 locus of the amt1-1 strain, in which the authentic AMT1 locus was disrupted by an insertion of the Salmonella his gene (Zhou and Thiele 1991).

Because our original AMT1 genomic clone lacks the $3^{\prime}$ untranslated sequences of this gene, which contains the $A M T 1$ transcription termination signal, we carried out inverse PCR (IPCR) and DNA cloning to isolate a 1.6-kb BglII-SpeI DNA restriction fragment that encompasses the entire AMT1 mRNA transcript (Ochman et al. 1990; GenBank accession number M69146). This experiment also allowed us to identify a short extragenic sequence that was ligated $3^{\prime}$ to the AMT1-coding sequence during our initial cloning; however, this did not alter the $A M T 1$ promoter or coding sequence.

\section{RNA analysis}

The steady-state levels of $A M T 1, M T-I$, and MT-II mRNA before or after induction by copper or other metal ions were analyzed by either RNA blotting or primer extension assays as described (Ausubel et al. 1987). C. glabrata wild-type 85/038, Q (ura3-), or amt1-1 cells containing episomal or integrative plasmids were grown to logarithmic phase and induced with different copper concentrations and time periods as indicated in each figure legend. Specific AMT1, MT-I, MT-II, URA3, and actin mRNA species were detected using ${ }^{32} \mathrm{P}$-labeled DNA fragments, respectively, as follows: $1.6-\mathrm{kb}$ BglII-SpeI (this paper; Zhou and Thiele 1991); 0.7-kb EcoRI-ApaI (Mehra et al. 1989); 0.7-kb EcoRI-SmaI (Mehra et al. 1990); 1.5-kb XhoI-PstI (P. Zhou, M. Szczypka, R. Young, and D. Theile, in prep.); and 1.6-kb HindIII ( $\mathrm{Ng}$ and Abelson 1980) DNA restriction fragments. It is noteworthy that the $M T-I I$ probe used in RNA blot hybridization detected both the MT-IIa and MT-IIb mRNAs. Deoxyoligonucleotides were synthesized for use as primers in extension reactions and were labeled at $5^{\prime}$ termini with polynucleotide kinase and $\left[\gamma^{-32} \mathrm{P}\right] \mathrm{ATP}$; the $A M T 1$-specific primer contained 26 nucleotides with the sequence $5^{\prime}$-GATTACTACCATGGTGCAAATGTGTG-3', complementary to nucleotide positions +65 to +40 of the $A M T 1$ gene (Zhou and Thiele 1991) and was used to determine the AMT1 transcription initiation sites. The $A M T 1$-specific primer was also employed in the primer extension reactions using the $A M T 1-l a c Z$ mRNA as a template. This experiment demonstrated that the transcription of the AMT1lacZ fusion gene initiated at sites identical to those of the authentic AMT1 gene (P. Zhou, unpubl.).

\section{Analysis of DNA-protein interactions}

AMT1 DNA-binding studies were carried out with partially purified AMT1 protein expressed in E. coli using the T7 RNA polymerase system (Studier et al. 1990; Zhou and Thiele 1991; Zhou et al. 1992). Electrophoretic mobility shift assays were used to detect binding of the copper-activated AMTl protein to the ${ }^{32}$ P-labeled 326-bp BglII-SspI DNA restriction fragments containing either the wild-type or mutant AMT1-binding site.

DNase I footprinting and methylation interference assays 
were used to map the AMTl-binding site within the AMT1 promoter. Two plasmids were constructed for the isolation of the AMT1 promoter DNA restriction fragment probes. The 326bp BglII-SspI fragment was inserted into the BamHI-EcoRV sites of pBluescript $\mathrm{SK}|+|$ to make plasmid pAMT1(U). The 369-bp MvaI-RsaI DNA restriction fragment was end-repaired by the Klenow fragment of DNA polymerase I and subcloned into the EcoRV site of pBluescript $\mathrm{SK}|+|$ to make plasmid pAMT1(L). Probes labeled on the coding or noncoding strand of the AMT1 promoter were prepared by digestion of PAMT1(U) and pAMT1 $|L|$ with appropriate restriction enzymes and then radiolabeled with $\left[\alpha-{ }^{32} \mathrm{P}\right] \mathrm{dCTP}$ and the Klenow fragment of DNA polymerase I (Ausubel et al. 1987). DNase I footprinting and methylation interference assays were carried out as described in detail (Aubusel et al. 1987; Zhou et al. 1992).

\section{${ }^{35} \mathrm{~S}$-Labeling of the MTs and gel electrophoresis}

To analyze the MT-I and MT-II protein levels in C. glabrata cells induced with copper, a 5-ml culture of the isogenic AMT1::URA3 and AMT1 $(\mathrm{m}):: U R A 3$ cells were grown to log phase in SC media lacking cysteine and methionine (SC - Cys - Met). Cells were pelleted and resuspended in 0.4 $\mathrm{ml}$ of SC - Cys - Met and incubated at $30^{\circ} \mathrm{C}$ for $10 \mathrm{~min}$ with shaking in the presence of $8.0 \mu \mathrm{l}$ of $\left.{ }^{35} \mathrm{~S}\right]$ cysteine (ICN, $227 \mu \mathrm{Ci}$ / $\mathrm{ml})$ and $\mathrm{CuSO}_{4}$ at concentrations indicated in Figure 8. Cells were then harvested, suspended in $400 \mu \mathrm{l}$ of lysis buffer (10.0 $\mathrm{mM}$ Tris- $\mathrm{HCl}$ at $\mathrm{pH} 7.8,10 \mathrm{~mm}$ PMSF, $1 \mathrm{~mm}$ dithiothreitol), and $400 \mu \mathrm{l}$ of acid-washed glass beads, and lysed by vortexing at top speed four times for $1 \mathrm{~min}$ each at $4^{\circ} \mathrm{C}$. The soluble proteins were isolated by centrifugation at $14,000 \mathrm{rpm}$ for $15 \mathrm{~min}$, and protein concentrations were determined by the Bradford assay (Aubusel et al. 1987). Protein $(1.0 \mu \mathrm{g}$ ) was treated with $500 \mu \mathrm{M}$ $\mathrm{CuSO}_{4}$ at room temperature for $10 \mathrm{~min}$. This step saturated MTs with copper and converted all MT-I and MT-II protein isoforms into the uniformly copper-coordinated conformations that migrate as distinct bands on native polyacrylamide gel (Fig. 8). Equal volumes of buffer $(0.1 \mathrm{M}$ Tris- $\mathrm{HCl}$ at $\mathrm{pH} 6.8,25 \%$ glycerol, 0.35 M 2-mercaptoethanol, $0.1 \%$ bromphenol blue) were added to each protein extract. The samples were then loaded on $25 \%$ nondenaturing polyacrylamide gels and subjected to electrophoresis at $200 \mathrm{~V}$ until the bromphenol blue reached the bottom of the gel. The proteins were fixed in the gel with $10 \%$ acetic acid and $30 \%$ methanol for $1 \mathrm{hr}$ and were fluorographed with $\mathrm{EN}^{3} \mathrm{HANCE}$ solution as described by the supplier (DuPont). The gel was then dried under vacuum and exposed to Kodak XAR-5 film with an intensifying screen at $-80^{\circ} \mathrm{C}$. $\left[{ }^{35} \mathrm{~S}\right]$ Cysteine-labeled protein extracts from C. glabrata 2001-L5 and RM4 (MT-IIaA, MT-IIbA) cells were coelectrophoresed on a $25 \%$ native polyacrylamide gel and served as controls to identify the MT-I and MT-II polypeptides. It should be noted that the MT-IIa and MT-IIb genes encode identical protein species, although their mRNA transcripts are slightly different in the 3' untranslated regions (Mehra et al. 1992).

\section{Acknowledgments}

We thank D. Engelke, D. Friedman, A. Seasholtz, and K. Koch for critical reading of the manuscript; members of the Thiele laboratory for helpful discussions; D. Winge and J. Thorvaldsen for generously providing us with the C. glabrata strains 2001L5, RM2, and RM4; L. Gedamu for advice on MT protein analysis; and R. Young for technical assistance. We are grateful to Geraldine Butler for providing information on the AMT1 nucleotide sequence. P.Z. was supported in part by a Rackham pre- doctoral fellowship from the Horace H. Rackham School of Graduate Studies at the University of Michigan and a Loeb predoctoral fellowship from the University of Michigan Cancer Center. This work was funded by grants GM41840 from the National Institutes of Health, and by grant M01-RR00042 to the General Clinical Research Center, University of Michigan Medical Center.

The publication costs of this article were defrayed in part by payment of page charges. This article must therefore be hereby marked "advertisement" in accordance with 18 USC section 1734 solely to indicate this fact.

\section{References}

Angel, P., K. Hattori, T. Smeal, and M. Karin. 1988. The jun proto-oncogene is positively autoregulated by its product, Jun/Ap-1. Cell 55: 875-885.

Ausubel, F.M., R. Brent, R.E. Kingston, D.D. Moore, J.G. Seidman, J.A. Smith, and K. Struhl, eds. 1987. Current protocols in molecular biology. Greene/Wiley, New York.

Barns, S.M., D.J. Lane, M.L. Sogin, C. Bibeau, and W.G. Weisburg. 1991. Evolutionary relationships among pathogenic Candida species and relatives. I. Bacteriol. 173: 2250-2255.

Buchman, C., P. Skroch, W. Dixon, T.D. Tullius, and M. Karin. 1990. A single amino acid change in CUP2 alters its mode of DNA-binding. Mol. Cell. Biol. 10: 4778-4787.

Butt, T.R., E. Sternberg, J. Herd, and S.T. Crooke. 1984. Cloning and expression of a yeast copper metallothionein gene. Gene 27: 23-33.

Evans, C.F., D.R. Engelke, and D.J. Thiele. 1990. ACEl transcription factor produced in Escherichia coli binds multiple regions within yeast metallothionein upstream activation sequences. Mol. Cell. Biol. 10: 426-429.

Falvey, E. and U. Schibler. 1991. How are the regulators regulated? FASEB $J$. 5: 309-314.

Fogel, S. and J. W. Welch. 1982. Tandem gene amplification mediates copper resistance in yeast. Proc. Natl. Acad. Sci. 79: 5342-5346.

Fürst, P., S. Hu, R. Hackett, and D.H. Hamer. 1988. Copper activates metallothionein gene transcription by altering the conformation of a specific DNA-binding protein. Cell 55: 705-717.

Gralla E.B., D.J. Thiele, P. Silar, and J.S. Valentine. 1991. ACE1, a copper-dependent transcription factor, activates expression of the yeast copper, zinc superoxide dismutase gene. Proc. Natl. Acad. Sci. 88: 8558-8562.

Halliwell, B. and J.M.C. Gutteridge. 1984. Oxygen toxicity, oxygen radicals, transition metals and disease. Biochem. $I$. 219: 1-14.

Hu, S., P. Fürst, and D.H. Hamer. 1990. The DNA and copper binding function of ACE1 are interdigitated within a single domain. New Biol. 2: 1-13.

Huibregste, J.M., D.R. Engelke, and D.J. Thiele. 1989. Copperinduced binding of cellular factors to yeast metallothionein upstream activation sequences. Proc. Natl. Acad. Sci. 86: 65-69.

Kägi, J.H.R. and Y. Kojima. 1987. Chemistry and biochemistry of metallothionein. In Metallothionein II (ed. J.H.R. Kägi and Y. Kojimal, pp. 25-61. Birkhäuser Verlag, Basel, Switzerland.

Kägi, J.H. and A. Schaffer. 1988. Biochemistry of metallothionein. Biochemistry 27: 8509-8515.

Karin, M., R. Najarain, A. Haslinger, P. Valenzuela, J.W. Welch, and S. Fogel. 1984. Primary structure and transcription of an amplified genetic locus: The CUP1 locus of yeast. Proc. Natl. Acad. Sci. 81: 337-341. 
Lin, C.M. and D.J. Kosman. 1990. Copper uptake in wild-type and copper metallothionein-deficient Saccharomyces cerevisiae. J. Biol. Chem. 265: 9194-9200.

Maloy, S. and V. Stewart. 1993. Autogenous regulation of gene expression. I. Bacteriol. 175: 307-316.

Mason, M.M., B.A. Lasker, and W.S. Riggsby. 1987. Molecular probes for identification of medically important Candida species and Torulopsis glabrata. J. Clin. Microbiol. 25: 563566.

Mehra, R.K., J.R. Garey, T.R. Butt, W.R. Gray, and D.R. Winge. 1989. Candida glabrata metallothioneins. I. Biol. Chem. 264: 19747-19753.

Mehra, R.K., J.R. Garey, and D.R. Winge. 1990. Selective and tandem amplification of a member of the metallothionein gene family in Candida glabrata. J. Biol. Chem. 265: 63696375.

Mehra, R.K., J.L. Thorvaldsen, I.G. Macreadie, and D.R. Winge. 1992. Disruption analysis of metallothionein-encoding genes in Candida glabrata. Gene 114: 75-80.

Myers, A.M., A. Tzagoloff, D.M. Kinney, and C.J. Lusty. 1986. Yeast shuttle and integrative vectors with multiple cloning sites suitable for construction of lacZ fusions. Gene 45: 299310.

$\mathrm{Ng}, \mathrm{R}$. and J. Abelson. 1980. Isolation and sequence of the gene for actin in Saccharomyces cerevisiae. Proc. Natl. Acad. Sci. 77: 3912-3916.

Ochman, H., M.M. Medhora, D. Garza, and D.L. Hartl. 1990. Amplification of flanking sequences by inverse PCR. In PCR protocols, a guide to methods and applications (ed. M.A. Innis, D.H. Gelfand, J.J. Sininsky, and T.J. White), pp. 219227. Academic Press, San Diego, CA.

Serfling, E. 1989. Autoregulation-A common property of eukaryotic transcription factors? Trends Genet. 5: 131-133.

Sikorski, R.S. and P. Hieter. 1989. A system of shuttle vectors and yeast host strains designed for efficient manipulation of DNA in Saccharomyces cerevisiae. Genetics 122: 19-27.

Sinnott, J.T., J.P. Cullison, and M.P. Sweeney. 1987. Candida (Torulopsis) glabrata. Infect. Control 8: 334-336.

Studier, F.W., A.H. Rosenberg, J.J. Dunn, and J.W. Dubendorff. 1990. Use of T7 RNA polymerase to direct expression of cloned genes. Methods Enzymol. 185: 60-89.

Szczypka, M.S. and D.J. Thiele. 1989. A cysteine-rich nuclear protein activates yeast metallothionein gene transcription. Mol. Cell. Biol. 9: 421-429.

Tamai, K.T., E.B. Gralla, L. Ellerby, J.S. Valentine and D.J. Thiele. 1993. Yeast and mammalian metallothioneins functionally substitute for yeast copper-zinc superoxide dismutase. Proc. Natl. Acad. Sci. (in press).

Thanos, D. and T. Maniatis. 1992. The high mobility group protein $\mathrm{HMG} \mathrm{I}(\mathrm{Y})$ is required for NF- $\mathrm{kB}$-dependent virus induction of the human IFN- $\beta$ gene. Cell 71: 777-789.

Thiele, D.J. 1988. ACE1 regulates expression of the Saccharomyces cerevisiae metallothionein gene. Mol. Cell. Biol. 8: $2745-2752$.

. 1992. Metal-regulated transcription in eukaryotes. $\mathrm{Nu}$ cleic Acids Res. 20: 1183-1191.

Zhou, P. and D.J. Thiele. 1991. Isolation of a metal-activated transcription factor gene in Candida glabrata by complementation in Saccharomyces cerevisiae. Proc. Natl. Acad. Sci. 88: 6112-6116.

Zhou, P., M.S. Szczypka, T. Sosinowski, and D.J. Thiele. 1992. Expression of a yeast metallothionein gene family is activated by a single metalloregulatory transcription factor. Mol. Cell. Biol. 12: 3766-3775. 


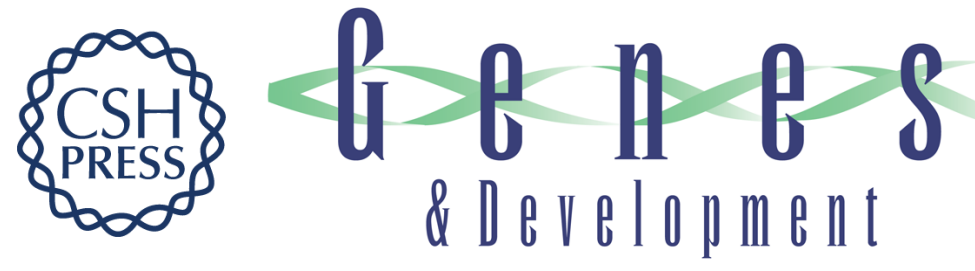

\section{Rapid transcriptional autoregulation of a yeast metalloregulatory transcription factor is essential for high-level copper detoxification.}

P Zhou and D J Thiele

Genes Dev. 1993, 7:

Access the most recent version at doi:10.1101/gad.7.9.1824

References This article cites 32 articles, 19 of which can be accessed free at: http://genesdev.cshlp.org/content/7/9/1824.full.html\#ref-list-1

License

Email Alerting

Service

Receive free email alerts when new articles cite this article - sign up in the box at the top right corner of the article or click here.

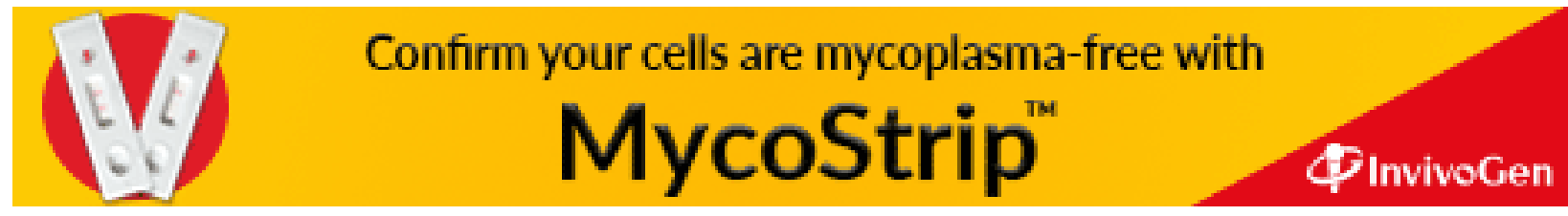

